\title{
Atividades Lúdicas e Artesanais Voltadas para o Tratamento de Pacientes Crônicos
}

\author{
Oliveira, Nathália Carvalho de; Oliveira, Ana Camila Ferreira de; Barata, Jaqueline Marques \\ Lara \\ Pontifícia Universidade Católica de Minas Gerais — nathalia_oliveira1994@hotmail.com
}

Introdução: Humanizar é ofertar atendimento de qualidade articulando os avanços tecnológicos com acolhimento, melhoria do ambiente de cuidado e da condição de trabalho do profissional (BRASIL, 2004). Pensando nisto, a política nacional de humanização vem para garantir a inseparabilidade entre a atenção e a gestão dos processos de produção de saúde e também para gerar autonomia dos profissionais, de modo que os mesmos sintam-se capazes e responsáveis por garantir o bem estar do paciente de forma integral. a hospitalização é algo que muda a rotina do paciente, gerando sentimentos confusos tanto no paciente quanto na família. o manejo dessa situação requer da equipe e principalmente da enfermagem, uma assistência diferenciada e peculiar a este processo (AZEVEDO et al, 2008). de acordo com essa definição, o ato de cuidar pressupõe colocar-se ao lado do sujeito, interessar-se pelo seu desconforto (AZEVEDO et al, 2008). Logo, é dever do profissional de saúde cuidar de maneira integral, promovendo a cura, seja ela física, espiritual, biológica ou emocional. Objetivos: Contribuir para melhor adaptação dos pacientes as novas rotinas, na tentativa de amenizar o processo da hospitalização tornando-o mais humanizado e promover melhor comunicação entre o paciente e a equipe. Métodos: Trata-se de um projeto onde serão desenvolvidas atividades lúdicas e artesanais uma vez por semana em três andares de um hospital público. As atividades serão realizadas em horários combinados com a equipe de enfermagem do andar. Pensando em promover o entretenimento e trabalhar os sentimentos e lembranças dos pacientes, desenvolveremos atividades lúdicas e artesanais (ex: bingo, jogo da memória, jogo da velha, contação de história, leitura de poema e outras formas de artesanato) promovendo maior interação social e confiança por parte deles, na equipe de saúde, uma vez que o lúdico propicia a quebra de amarras sociais. Resultados: ao sofrer uma internação hospitalar os pacientes parecem encontrar-se no momento de suspensão, no "entre", entre o antes e depois da internação, entre a espera para realizar um exame e obter seus resultados, entre o tempo para se recuperar e obter alta. (PIMENTEL 2013). com o projeto esperamos preencher estes momentos de suspensão com atividades que favoreçam a comunicação, buscando ajudá-los a entender a situação que está vivendo no momento. Conclusão: As atividades lúdicas e artesanais contribuem de forma significativa para o desenvolvimento do ser humano, auxiliando não só na aprendizagem, mas facilitando também o processo de interação social e a construção do pensamento. Visto isso, concluímos que projetos como esse, são essenciais para melhorar a qualidade de vida dos pacientes que necessitam de hospitalização por muito tempo, além de contribuir para o processo de formação dos futuros profissionais de saúde, envolvidos na implementação destas atividades.

Oliveira, Nathália Carvalho de; Oliveira, Ana Camila Ferreira de; Barata, Jaqueline Marques Lara. Atividades Lúdicas e Artesanais Voltadas para o Tratamento de Pacientes Crônicos. In: Anais do Congresso Internacional de Humanidades \& Humanização em Saúde [= Blucher Medical Proceedings, num.2, vol.1]. São Paulo: Editora Blucher, 2014. ISSN 2357-7282

DOI 10.5151/medpro-cihhs-10640 